\title{
Non-invasive identification of paint binders in illuminated manuscripts by ER-FTIR spectroscopy: a systematic study of the influence of different pigments on the binders' characteristic spectral features
}

\author{
Luca Nodari ${ }^{1,2^{*}}$ and Paola Ricciardi ${ }^{3}$
}

\begin{abstract}
This paper presents the results of a study of pigment-binder systems painted on parchment, both in the form of reference samples prepared in the laboratory, and of medieval and Renaissance illuminated manuscripts, by means of contactless Fourier-transform mid-infrared spectroscopy (FTIR). The research is aimed at validating external reflection FTIR (ER-FTIR) as a non-invasive method for the identification of paint binders in works of art on parchment. Based on a systematic FTIR investigation undertaken both in attenuated total reflection (ATR) and ER mode, we discuss the possibility to effectively discriminate between different binders, and the way in which the presence of a number of pigments can modify the spectral features of the pigment-binder system. The study reveals that gum Arabic can usually be discriminated from egg-based binders such as egg yolk and egg white, both in paintouts and in real artworks. Amongst all the pigments investigated, carbonates such as azurite and lead white are those that most significantly hinder the correct identification of the paint medium.
\end{abstract}

Keywords: ER-FTIR spectroscopy, Illuminated manuscripts, Paint binders, Pigments

\section{Introduction}

Infrared spectroscopy is a well-established and widely used analytical technique in the heritage science field. The reasons of its success are to be found both in its wide applicability and in the significant instrumental developments from the 1970s to this day. By the 1980s, infrared spectroscopy had 'become an invaluable and extremely flexible tool for the analysis of nearly all artistic materials, from the classic to contemporary ones' [1]. The last thirty years have seen this trend confirmed, as the number of publications concerning the application of FTIR spectroscopy to the study of heritage materials has grown

*Correspondence: luca.nodari@cnr.it

${ }^{1}$ Institute of Condensed Matter Chemistry and Technology for Energy, National Research Council (ICMATE-CNR), C.so Stati Uniti 40, 35127 Padua, Italy

Full list of author information is available at the end of the article dramatically. The strength of mid-infrared spectroscopy has traditionally lied not only in its ability to recognize classes of compounds but also in the small amount of material that is needed for the analysis. In the last two decades however, the development of portable, contactless, FTIR spectrometers operating in external reflection, has also allowed the beginning of non-invasive mid-infrared spectroscopy analyses on cultural heritage materials [2 and references therein]. ER-FTIR is totally non-invasive because it does not require sampling or even contact with the object, which can be placed a short distance (approximately $1 \mathrm{~mm}$ ) from the instrument. The instrumentation is often portable and therefore suitable for in situ analysis, which is a definite advantage for the study of artworks. Another benefit consists in the possibility to collect spectra in a broad spectral range, which includes the near-infrared $\left(7500-400 \mathrm{~cm}^{-1}\right.$, i.e. $1330-25,000 \mathrm{~nm})$. Despite its versatility, ER-FTIR shows 
a significant drawback in the spectral interpretation. The complexity of the spectra, in the form of bands distortions and variations of their intensity ratio, is ascribable to the specular $\left(R_{\mathrm{s}}\right)$ and volume $\left(\mathrm{R}_{\mathrm{v}}\right)$ components of the reflected radiation. While the former causes derivativelike distortions in the band shape and/or band inversion (reststrahlen effect), the latter enhances the intensity of the weakest bands, such as overtones and combination bands. Since both the physical properties (e.g. morphology, particles size, surface roughness) and the optical properties (absorption and refractive indices) of the substrate can influence the penetration of the incident radiation, the spectral features will be affected by the different contribution of $R_{s}$ and $R_{v}$. Such spectral distortions are usually not present, or evident, in FTIR spectra collected in attenuated total reflection mode (both in ATR or micro-ATR mode); this approach, however, requires either a microscopic sample or the application of significant pressure on the surface under analysis, and is therefore often not suitable for the analysis of works of art. In the majority of cases, ATR spectra can be interpreted by (automated) comparison with spectral databases, which are usually sold with the instrument itself. This is not usually possible with spectra collected in ER-FTIR mode.

While the ATR and $\mu$-ATR are widely used in the characterization of Illuminations and manuscripts [3-6], the use of ER-FTIR is still limited [7-9]. The main goal of the present study is the evaluation of the possibility to discriminate the different classes of binders, e.g. lipids vs. proteins vs. carbohydrates, when they are mixed with different pigments. In particular, we focused our attention on the influence of the pigments' vibrational features on the position and distortion of the organic binder's marker bands. The use of organic binders, with good filmogenic properties, often produces very smooth pictorial layers, in which the inorganic pigments are embedded. In terms of reflection, the smoothness of the surface enhances the $R_{S}$ component, and in the case of inorganic pigments such as carbonates, the result is the appearance of intense reststrahlen bands [2]. The superposition between inverted absorption and derivative-like distorted bands, typical of organic compounds, can give rise to very complex spectra. To understand how pigments can influence the marker bands' position, a preliminary comparison among $\mu$-ATR and ER-FTIR spectra was performed. About 100 paintouts on parchment, representative of pure binders and pigment-binder systems, were studied. These paintouts were designed to replicate the structure of paint layers on western European manuscripts produced during the Middle Ages and the Renaissance. Before discussing the discrimination among different binders and/or pigments, the spectral features of the samples prepared by painting each pure binder over parchment are presented, and their vibrational bands attributed to specific functional groups. As mentioned, ER-FTIR spectra can differ substantially from those collected in other configurations, including ATR mode. This can be very well illustrated by a comparison of ER-FTIR and ATR spectra of pure binders painted on parchment, which also facilitates the attribution of absorption bands identified in the ER-FTIR spectra. After a thorough review of the paint layers' spectral features, selected areas were also analysed in a number of manuscript cuttings and bound volumes.

\section{Materials and methods}

The paintouts were prepared by brush coating natural parchment with different pigment/binder mixtures. Each pigment was bound with four different paint binders, chosen to simulate mediaeval and Renaissance illuminations: gum Arabic (GA), egg yolk (EY), egg white (albumen, EW) and whole egg (WE) were chosen. The pigments were also chosen to span the colour range of those most widely used in illuminations and included blue (azurite, ultramarine, indigo and smalt), yellow (lead-tin yellow I), red (vermilion, red lead, madder lake, lac lake), white (gypsum, chalk, lead white) and green (malachite, verdigris, green earth) ones. The paintouts' thickness was not directly measured, but based on similar lab-made samples, the paint layers are estimated to be between 10 and 200 microns thick.

Infrared spectra were acquired using a portable contactless Bruker Alpha spectrometer operating in the $7500-400 \mathrm{~cm}^{-1}$ range. Forty scans, with a resolution of $4 \mathrm{~cm}^{-1}$, were performed for each measurements and the analysed area was around $5 \mathrm{~mm}$ in diameter. MicroATR spectra were collected on the paintouts using a Spectra Tech Continuum optical microscope, mounting a Si ATR objective, coupled to a Thermo Scientific Nicolet iS 10 and equipped with an MCT detector. The spectra (64 scans) were collected in the $4000-650 \mathrm{~cm}^{-1}$ range with a resolution of $4 \mathrm{~cm}^{-1}$. As is well known [2], spectra collected in external reflection mode can be extremely different from those collected in transmission mode. The attribution of spectral bands to specific vibrational modes was therefore based on a comparison with the spectra collected in $\mu$-ATR mode. The presence of derivative-like distortions or inverted bands was evaluated case by case, taking into account the complexity of the spectrum and the physical nature of the paint film. Due to the chemical and physical heterogeneity of the investigated sample, the Kramers-Kronig transformation was not applied. The spectra were only smoothed using the Savitzky Golay algorithm available in the instrument's own spectral acquisition software. 


\section{Results and discussion: paintouts Parchment}

The parchment support, prepared by processing animal skin, is mainly composed of collagen, a polypeptidic material which gives rise to two characteristic amide bands, amide I (hereafter AI) and amide II (hereafter AII). According to the literature [5, 10], AI and AII are centred at 1693 and $1547 \mathrm{~cm}^{-1}$ respectively in the $\mu$-ATR spectrum, whereas in ER-FTIR they both show a typical derivative-like distortion, with the inflection points centred at 1662 and $1555 \mathrm{~cm}^{-1}$ respectively (Fig. 1a). Also the $\mathrm{N}-\mathrm{H}$ stretching, whose shape and position are well-defined in $\mu$-ATR spectrum, appears distorted and weakened in intensity in the ER-FTIR spectrum. In the $4000-6000 \mathrm{~cm}^{-1}$ region, one finds a distinctive absorption for proteinaceous material, that is the $v+\delta(N-H)$ combination band [11] centred at $\approx 4890 \mathrm{~cm}^{-1}$. The AI, AII and $v+\delta(\mathrm{N}-\mathrm{H})$ combination bands will therefore be markers not only for parchment but also for any pure proteinaceous binder, such as egg white.

\section{Pure binders on parchment: ATR vs. ER-FTIR spectra}

Due to the glossy nature of the gum Arabic layer, the GA ER-FTIR spectrum (Fig. 1b) is dominated by the strong and distorted bands-both stretching $(v(\mathrm{OH}))$ and bending $(\delta(\mathrm{OH})$ ) - of the hydroxyl functional groups in polysaccharide units. The former, centred at $3320 \mathrm{~cm}^{-1}$ in the $\mu$-ATR spectrum, appears to be distorted, with clear derivative features, showing an inflection point at $\approx 3350 \mathrm{~cm}^{-1}$. The latter, centred at $1604 \mathrm{~cm}^{-1}$ in the $\mu$-ATR spectrum, presents a broad absorption, partially affected by derivative distortion, in the $1900-1600 \mathrm{~cm}^{-1}$ range. The absorption broadening can be attributed to the overlap between the distorted $\delta(\mathrm{OH})$, with an inflection point at $\approx 1604 \mathrm{~cm}^{-1}$, and a carboxylate stretching band, present as a shoulder in the $\mu$-ATR spectrum $\left(\approx 1643 \mathrm{~cm}^{-1}\right)$. The presence of $\mathrm{vCOO}^{-}$band can be representative of a partial hydrolysis of the polysaccharide units.

The $v(\mathrm{C}-\mathrm{O})$ of the glycosidic bond displays an intense inverted band at $1020 \mathrm{~cm}^{-1}$. In the spectral region above $4000 \mathrm{~cm}^{-1}$, the absorption features are due to combination bands and overtones of the principal vibrational modes of the polysaccharide structure. They are, however, often superimposed with those originating from the substrate (parchment) and/or too broad and weak to be useful diagnostic tools. When trying to distinguish gum Arabic from other binders, the $v(\mathrm{OH})$ band also cannot be used as a characteristic marker, because it is often overlapped by the $\mathrm{NH}$ and/or $\mathrm{OH}$ stretching absorptions typical of the investigated materials (i.e. parchment and pigments). However distorted, it is the band assigned to
$\delta(\mathrm{OH})$ that can be used reliably to distinguish gum Arabic from the other binders studied here.

Egg based binders, i.e. egg yolk, egg white and whole egg show rather complex spectra, with variations depending both on the chemical and on the physical features of the paint layer (Fig. 1c-e). The main chemical difference between these three binders is the fact that EW is a purely proteinaceous binder, whereas EY and WE also contain a lipidic fraction. Their spectra will therefore show, in addition to the two amide bands, also the lipid features. Generally speaking, the presence of a lipidic component can be easily detected by the intense $\mathrm{C}=\mathrm{O}$ asymmetric stretching and by the typical $v+\delta(\mathrm{CH})$ combination bands [12]. The former usually displays a feature with a typical derivative-like shape, detectable in the $1800-1700 \mathrm{~cm}^{-1}$ range. Usually broad but well defined, it is centered around $\approx 1740 \mathrm{~cm}^{-1}$ when the derivative distortion component is low. The latter, undistorted and centered at 4399 and $4266 \mathrm{~cm}^{-1}$, are well distinguishable in both pure EY (Fig. 1c) and WE (Fig. 1e), as well as in most of the binder/pigment systems, as will be discussed later. It is worth noting that also the broad band at $\approx 5800 \mathrm{~cm}^{-1}$, due to the first overtone of the $\mathrm{CH}_{2}$ asymmetric stretching, is typical of natural lipid-containing binders; it can be used to support our attribution. For all three egg-based binders, the amide I and II bands are located at approximately 1693 and $1560 \mathrm{~cm}^{-1}$, respectively. Common to all proteinaceous materials, the $\mathrm{N}-\mathrm{H}$ stretching bands, between 3360 and $3660 \mathrm{~cm}^{-1}$, are not well detectable in egg-based binders and can therefore not be easily used as markers for their identification.

Overall, these observations suggest that-at least in these simple 'model' systems-distinction amongst these four different binders painted on a parchment support is usually possible using ER-FTIR spectroscopy, thanks to the presence of specific 'marker' bands: GA is easily distinguishable from egg-based media; EY can be further discriminated from EW because of its lipidic content (Fig. 2). WE, however, can easily be confused with EY or with EW, depending on the presence or absence of the characteristic absorption bands of lipids in the individual spectrum, which in turn depends on the lipidic fraction concentration in the sample. It is worth observing that, if the binder layer is very thin, the signals due to the substrate can also be identified, because-depending on the specific features of each individual sample - the incident radiation can penetrate the sample up to a depth of several tens of microns. With the exclusion of EW, the parchment's absorption, however, does not significantly affect the intensity and shape of the main absorptions due to the pure binders, as measured on samples of binders painted on glass slide (spectra not shown). Only the $v+\delta(\mathrm{N}-\mathrm{H})$ at 

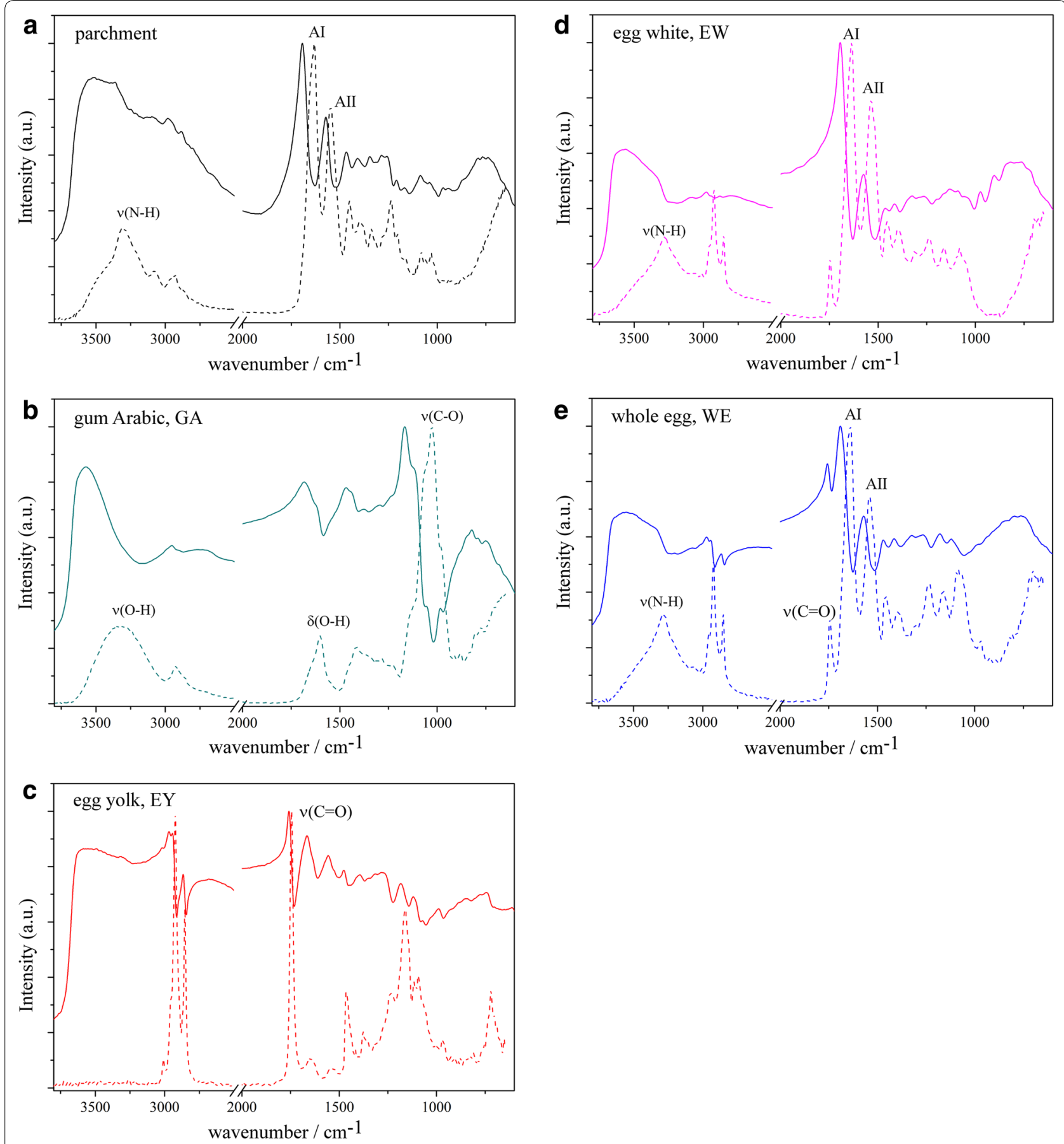

Fig. 1 Comparison between ER-FTIR and $\mu$-ATR measurements on: a parchment; $\mathbf{b}$ gum Arabic; c egg yolk; $\mathbf{d}$ egg white and e whole egg. The main absorption region of interest is enlarged in the boxes. Dotted lines refers to the spectra collected in $\mu$-ATR mode

$4880 \mathrm{~cm}^{-1}$ is observed in particularly thin GA paints. Also a broadening in the $\mathrm{O}-\mathrm{H}$ stretching region, due to the superimposition of the intense signals of both substrate and paint binders, is sometimes observed.
As already mentioned, the paintouts were also investigated by $\mu$-ATR, in order to understand how the ER configuration modifies the IR spectral features. During that experiment we observed that $\mu$-ATR spectra are not always representative of all the functional groups present 


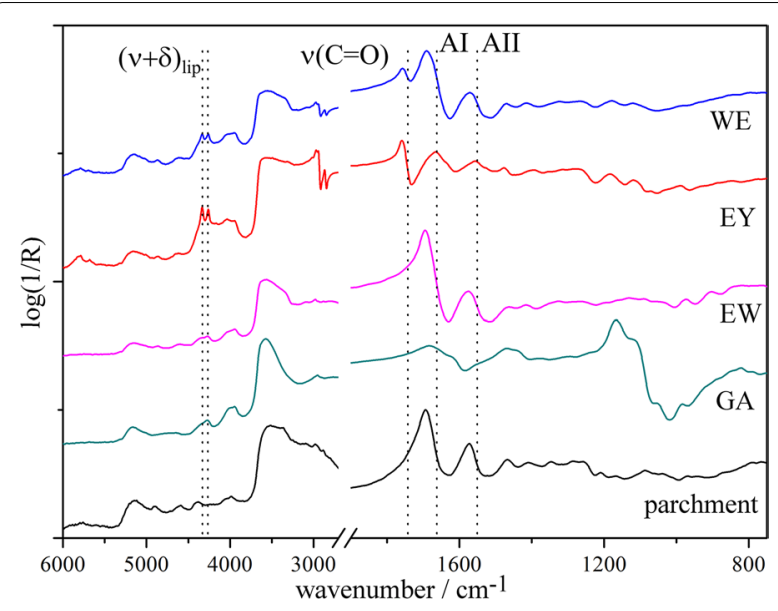

Fig. 2 Comparison between the ER-FTIR spectra collected on unpainted parchment and on different binders painted on parchment. From bottom to top: parchment (black), gum Arabic (dark cyan), egg white (magenta), egg yolk (red) and whole egg (blue). The main diagnostic bands are indicated

in the paint layer. This behavior is related to the physical properties, i.e. hardness and/or rigidity, of the paint film, and with the fact that the $\mu$-ATR crystal needs to be in 'intimate' contact with small portion of the sample surface $\left(\approx 50 \mu \mathrm{m}^{2}\right)$ in order to obtain a spectrum. Such close contact is achieved by applying a significant pressure on the sample. If the film is brittle, as was found to be the case for EW and WE, the applied pressure is high enough to induce fractures and de-cohesion of the pictorial layer. Considering also that the pictorial layer can be heterogeneous at the $\mu$-ATR scale, the resulting spectrum is liable to contain only the pigments' absorptions (in pigmentbinder systems). This is attributable to the formation of pigments aggregates, poor in binder, and hard enough to contrast the crystal pressure. More elastic binders such as EY, on the other hand, create a flexible film, which bends under the crystal's pressure, without fracturing, so that the resulting spectrum is representative of both binder and pigment. In most cases, this problem is overcome by ER-FTIR, which requires no contact with the sample, so that the spectra collected are fully representative of the entire pictorial layer.

\section{Pigment-binder systems}

The study of slightly more complex systems, made up of individual pigments or binary mixtures bound in one of the four binders and then painted on parchment, was mainly aimed at establishing the possible effects of each pigment on the position and/or the type of distortion of the marker bands identified for each binding medium. Blue, white, green, yellow and red mineral pigments containing carbonates, sulphates, silicates and oxides, were thoroughly characterized; bands assignments based on literature data $[2,13-15]$ are reported in Table 1.

As discussed, the region between 1900 and $1500 \mathrm{~cm}^{-1}$ is the main region of interest for the GA, EY, EW and WE marker bands. The binder's identification is quite straightforward when the system contains pigments such as oxides (minium, lead-tin yellow), silicates (earths, smalt, natural and French ultramarine) or sulphides (vermillion). These compounds only show absorptions below about $1000 \mathrm{~cm}^{-1}$, and the spectra collected on the paintouts are quite similar to those of the pure binders (e.g. Fig. 3a-c). However, when the paint layer contains carbonate-based pigments, the spectral region between 1900 and $1500 \mathrm{~cm}^{-1}$ appears drastically affected by the pigment's main absorption. In fact, as results of the strong absorption coefficient of the $v_{3}\left(\mathrm{CO}_{3}^{=}\right)$, carbonatecontaining paintouts usually show spectra dominated by an intense and broad inverted band in the 1500$1400 \mathrm{~cm}^{-1}$ region. Moreover, if the surface is sufficiently rough, the volume reflection, $R_{V}$, increases the intensity of the $v_{1}+v_{4}$ combination band, whose position can interfere with the $\mathrm{C}=\mathrm{O}$ asymmetric stretching of lipids. As illustrated in Fig. 3d in the case of chalk, the spectrum is dominated by the pigment's characteristic absorption and the discrimination between GA and egg-based binders is rather difficult. Only the lipid fraction is detectable by the $\mathrm{C}=\mathrm{O}$ stretching. In that series of paintouts, the presence of a proteinaceous binder can only be inferred by the presence of $\mathrm{N}-\mathrm{H}$ stretching (Fig. 2b). In the lead white paintouts (Fig. 3e), EW and WE show really close spectral features because of the presence of the pigment's $v_{1}+v_{4}\left(\mathrm{CO}_{3}\right)$ combination band at $1740 \mathrm{~cm}^{-1}$. The $v(\mathrm{C}=\mathrm{O})$ contribution is hidden and the $v(\mathrm{~N}-\mathrm{H})$ one is similar in both cases, making the discrimination between the two binders virtually impossible. Differently from the chalk-containing paintouts, in the lead white system the presence of GA can be hypothesized by the presence of a broad $\delta(\mathrm{OH})$ feature.

The region of combination and overtone bands, lying between 6500 and $3500 \mathrm{~cm}^{-1}$, cannot be considered diagnostic for binders in most of the cases studied here. Only pure EY can be identify by $v+\delta(\mathrm{CH})$ combination bands. In general, due to the complexity of the investigated systems, that region often contains signals generated by the superposition of combination/overtone bands due to the various components of the pictorial layer. This is particularly true when paintouts contain azurite, and in some cases malachite, mixed with EY or WE. The $3 v_{3}\left(\mathrm{CO}_{3}^{\overline{ }}\right)$ and $v+\delta(\mathrm{OH})$ absorptions of both copper carbonates are very close to the $v+\delta(\mathrm{CH})$ combination bands of the lipid fraction, and the resulting overlap makes the binder's bands barely distinguishable (Fig. 3f). Interestingly, however, this same spectral region can be used to identify 
Table 1 Position and attribution of the marker bands for binders and selected blue, white and green pigments

\begin{tabular}{|c|c|c|c|}
\hline Pigment/binder & Wavenumber $\left(\mathrm{cm}^{-1}\right)$ & Assignment & Distortion type \\
\hline \multirow[t]{3}{*}{ Gum Arabic, polysaccharide } & 3350 & $v(\mathrm{O}-\mathrm{H})$ & Derivative \\
\hline & 1604 & $\delta(\mathrm{O}-\mathrm{H})$ & Derivative \\
\hline & 1020 & $v(C-O)$ & Inverted \\
\hline \multirow[t]{2}{*}{ Egg yolk, lipid + proteinaceous } & 4399,4266 & $v+\delta(C-H)$ & \\
\hline & 1740 & $v(C=O)$ & Derivative \\
\hline \multirow[t]{2}{*}{ Egg white, proteinaceous } & 1693 & Al & Derivative \\
\hline & 1560 & All & Derivative \\
\hline \multirow[t]{3}{*}{ Whole egg, lipid + proteinaceous } & 1740 & $v(C=O)$ & Derivative \\
\hline & 1693 & Al & Derivative \\
\hline & 1560 & All & Derivative \\
\hline \multirow{3}{*}{ Natural ultramarine, $\mathrm{Na}_{3} \mathrm{Ca}\left(\mathrm{Al}_{3} \mathrm{Si}_{3} \mathrm{O}_{12}\right) \mathrm{S}$} & 2343 & $\mathrm{~V}_{3}\left(\mathrm{CO}_{2}\right)$ & \\
\hline & $\approx 2100$ & $2 v(\mathrm{Si}-\mathrm{O})$ & \\
\hline & 1016 & $v(\mathrm{Si}-\mathrm{O})$ & Inverted \\
\hline \multirow[t]{2}{*}{ French (synthetic) ultramarine, $\mathrm{Na}_{3} \mathrm{Ca}\left(\mathrm{Al}_{3} \mathrm{Si}_{3} \mathrm{O}_{12}\right) \mathrm{S}$} & $\approx 2100$ & $2 v(\mathrm{Si}-\mathrm{O})$ & \\
\hline & 1022 & $v(\mathrm{Si}-\mathrm{O})$ & Inverted \\
\hline \multirow{8}{*}{ Azurite, $\mathrm{Cu}_{3}\left(\mathrm{CO}_{3}\right)_{2}(\mathrm{OH})_{2}$} & 4375,4252 & $3 v_{3}$ and $v+\delta(O-H)$ & \\
\hline & $2589,2550,2501$ & $v_{1}+v_{3}$ and/or $2 v_{2}+v_{4}$ & \\
\hline & 1881 & $v_{1}+v_{4}$ & \\
\hline & 1500 & $v_{3}$ & Inverted \\
\hline & 1090 & $v_{1}$ & Derivative \\
\hline & 820 & $v_{2}$ & Derivative \\
\hline & 744 & $v_{4}$ & Derivative \\
\hline & 563,505 & $v(\mathrm{Cu}-\mathrm{O})$ & Inverted \\
\hline \multirow[t]{2}{*}{ Smalt, Cobalt-bearing silicate glass } & $\approx 2100$ & $2 v(\mathrm{Si}-\mathrm{O})$ & \\
\hline & 1083 & $v(\mathrm{Si}-\mathrm{O})$ & Inverted \\
\hline \multirow[t]{6}{*}{ Calcite, $\mathrm{CaCO}_{3}$} & 4268 & $3 v_{3}$ & \\
\hline & $\approx 2514+2591$ & $v_{1}+v_{3}$ and/or $2 v_{2}+v_{4}$ & \\
\hline & 1796 & $v_{1}+v_{4}$ & \\
\hline & $\approx 1560$ & $v_{3}$ & Inverted \\
\hline & $\approx 881$ & $v_{2}$ & Derivative \\
\hline & $\approx 715$ & $v_{4}$ & Derivative \\
\hline \multirow[t]{7}{*}{ Lead white (hydrocerussite), $\mathrm{Pb}_{3}\left(\mathrm{CO}_{3}\right)_{2}(\mathrm{OH})_{2}$} & 4340 & $3 v_{3}$ and $v+\delta(\mathrm{O}-\mathrm{H})$ & \\
\hline & 3566 & $v(\mathrm{O}-\mathrm{H})$ & Derivative \\
\hline & 2428 & $v_{1}+v_{3}$ and/or $2 v_{2}+v_{4}$ & \\
\hline & 1740 & $v_{1}+v_{4}$ & \\
\hline & 1415 & $v_{3}$ & Inverted \\
\hline & 834 & $v_{2}$ & Derivative \\
\hline & 690 & $v_{4}$ & Derivative \\
\hline \multirow[t]{6}{*}{ Gypsum, $\mathrm{CaSO}_{4} \cdot 2 \mathrm{H}_{2} \mathrm{O}$} & 5136,5064 sh & $v_{1} / v_{3}(\mathrm{O}-\mathrm{H})+v_{2}(\mathrm{O}-\mathrm{H})$ & \\
\hline & $3548,3500,3435$ & $v(\mathrm{O}-\mathrm{H})$ & Derivative \\
\hline & 2233 & $2 v_{3}, v_{2}+v_{L} H_{2} \mathrm{O}$ & \\
\hline & 2124 & $v_{1}+v_{3}$ & \\
\hline & 1146 & $v_{3}$ & Inverted \\
\hline & 674 & $v_{4}$ & Inverted \\
\hline
\end{tabular}


Table 1 (continued)

\begin{tabular}{|c|c|c|c|}
\hline Pigment/binder & Wavenumber $\left(\mathrm{cm}^{-1}\right)$ & Assignment & Distortion type \\
\hline \multirow[t]{9}{*}{ Malachite, $\mathrm{Cu}_{2} \mathrm{CO}_{3}(\mathrm{OH})_{2}$} & 4401,4252 & $3 v_{3}$ and $v+\delta(O-H)$ & \\
\hline & 3423 & $v(\mathrm{O}-\mathrm{H})$ & \\
\hline & 2541,2422 & $v_{1}+v_{3}$ and/or $2 v_{2}+v_{4,} 0$ & \\
\hline & 1798 & $v_{1}+v_{4}$ & \\
\hline & 1466,1431 & $v_{3}$ & Inverted \\
\hline & 1081 & $v_{1}$ & Derivative \\
\hline & 952 & $\delta(\mathrm{O}-\mathrm{H})$ & \\
\hline & 837 & $v_{2}$ & Derivative \\
\hline & 452 & $v(\mathrm{Cu}-\mathrm{O})$ & Inverted \\
\hline \multirow[t]{3}{*}{ Green earth, $\mathrm{K}\left(\mathrm{Mg}, \mathrm{Fe}^{2+}\right)\left(\mathrm{Fe}^{3+}, \mathrm{Al}\right)\left[\mathrm{Si}_{4} \mathrm{O}_{10}\right](\mathrm{OH})_{2}$} & 3575,3673 & $\mathrm{VO}-\mathrm{H}$ & \\
\hline & $\approx 2100$ & $2 v(\mathrm{Si}-\mathrm{O})$ & \\
\hline & 1029 & $v(\mathrm{Si}-\mathrm{O})$ & Inverted \\
\hline \multirow[t]{4}{*}{ Lead-tin yellow, $\mathrm{Pb}_{2} \mathrm{SnO}_{4}$} & 569 & $v\left(\mathrm{~Pb}_{2} \mathrm{SnO}_{4}\right)$ & Inverted \\
\hline & 504 & $v\left(\mathrm{~Pb}_{2} \mathrm{SnO}_{4}\right)$ & Inverted \\
\hline & 459 & $\mathrm{v}\left(\mathrm{Pb}_{2} \mathrm{SnO}_{4}\right)$ & Inverted \\
\hline & 427 & $v\left(\mathrm{~Pb}_{2} \mathrm{SnO}_{4}\right)$ & Inverted \\
\hline \multirow[t]{2}{*}{ Minium, $\mathrm{Pb}_{3} \mathrm{O}_{4}$} & 525 & $v(\mathrm{~Pb}-\mathrm{O})$ & Inverted \\
\hline & 435 & $v(\mathrm{~Pb}-\mathrm{O})$ & Inverted \\
\hline
\end{tabular}

The data refers to the spectra collected in ER-FTIR mode. The pigments' assignments are related to the paintouts bound in egg white. Combination and overtones do not show any distortions; when the absorptions are affected by derivative-like distortion, the wavenumber is related to the inflection point; sh stands for shoulder. Attributions are based on previous literature, cited in the text

lipid-containing binders, even in the presence of copper carbonates, using fiber optic reflectance spectroscopy (FORS) systems operating in the visible and near-infrared range (up to $2500 \mathrm{~nm}$, corresponding to $4000 \mathrm{~cm}^{-1}$ ) [16].

Considering the evidence provided by these results, the best chances for a clear identification of the paint binder used in real manuscript illuminations are tied to the possibility of collecting spectra in areas painted with simple oxide and sulphide-based pigments such as minium, orpiment and vermillion, all three of which were used extensively by medieval and Renaissance illuminators. This is particularly true when the pictorial layer is thick enough to (at least partially) hide the parchment's spectral contribution and/or when the paint layer has not been modelled with white carbonates.

\section{Results and discussion: case studies}

The practical benefits of using ER-FTIR to study illuminated manuscripts can be best illustrated by a few case studies, all relative to objects in the collection of the Fitzwilliam Museum in Cambridge, UK. The main goal of the analysis was the identification of the binder(s) used to paint each illumination. In some cases, we were also hoping to obtain results that would support the identification of pigments, based on previous analyses by means of other non-invasive methods such as X-ray fluorescence (XRF) and fibre-optics reflectance spectroscopy (FORS) [17]. The three case studies discussed here show how ER-FTIR can often, although not always, be used to answer this type of research questions.

\section{A fifteenth-century leaf by Jean Bourdichon}

A late fifteenth-century leaf from a Book of Hours, painted by the workshop of renowned French artist Jean Bourdichon (Cambridge, Fitzwilliam Museum, Marlay Cutting Fr. 5, Fig. 4a), was analysed with the aim of identifying the paint binder used and to confirm the nature of the blue and green pigments.

ER-FTIR analysis provided a good spectral match between the spectra collected on several areas of the fragment and the pure GA reference and/or the paintouts with pigments bound in GA (e.g. see Fig. 4c). The presence of gum Arabic in an illuminated fragment of this period and origin is expected.

The IR spectrum collected on the green garment (Fig. 4b) shows the typical shape of an absorption spectrum, without significant distortions except for some reststrahlen bands at low wavenumbers. The presence of natural ultramarine is clearly recognizable from the sharp signal at $2343 \mathrm{~cm}^{-1}$, together with an inverted band at $1021 \mathrm{~cm}^{-1}$. The presence of the sharp absorption at $2342 \mathrm{~cm}^{-1}$, due to the $\mathrm{CO}_{2}$ entrapped in the sodalite cage [18], is typical of the natural pigment. On the contrary, the synthetic one, the so called French ultramarine, does not show this absorption. The analysis of the higher wavenumbers spectral region (above $4000 \mathrm{~cm}^{-1}$ ) reveals 

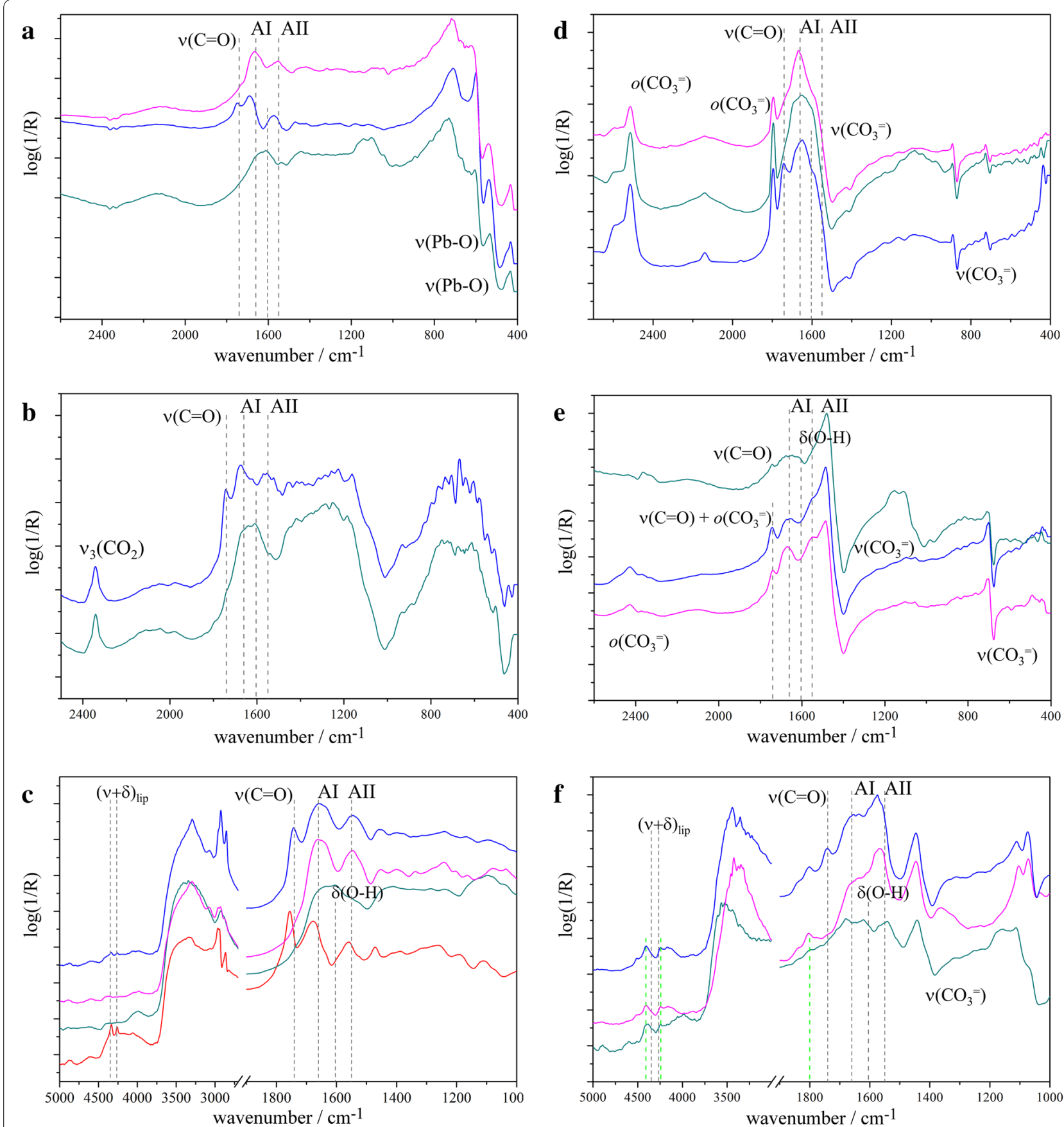

Fig. 3 Comparison between ER-FTIR spectra collected on paintouts containing various pigments bound in gum Arabic (dark cyan spectra), egg white (magenta), egg yolk (red) and whole egg (blue): a lead-tin yellow; b natural ultramarine; c vermilion; $\mathbf{d}$ chalk; e lead white; $\mathbf{f}$ malachite, with green dashed lines representative of malachite overtones and combination bands. In each spectrum the pigment's overtones and/or combination bands are labeled with o(functional group)

the presence of two sharp absorptions, centred at 4380 and $4242 \mathrm{~cm}^{-1}$ respectively, which are definitive indicators of the presence of azurite. These signals are due both to an overtone $\left(3 v_{3} \mathrm{CO}_{3}^{=}\right)$and to the combination of the $\mathrm{OH}^{-}$stretching and bending. Interestingly, analysing the region of interest between 2600 and $2500 \mathrm{~cm}^{-1}$, we detected no signals that could clearly be assigned to the typical $v\left(\mathrm{CO}_{3}\right)$ combination bands of azurite. The green colour appears therefore to be a complex mixture of blue and yellow pigments, i.e. azurite, ultramarine and 

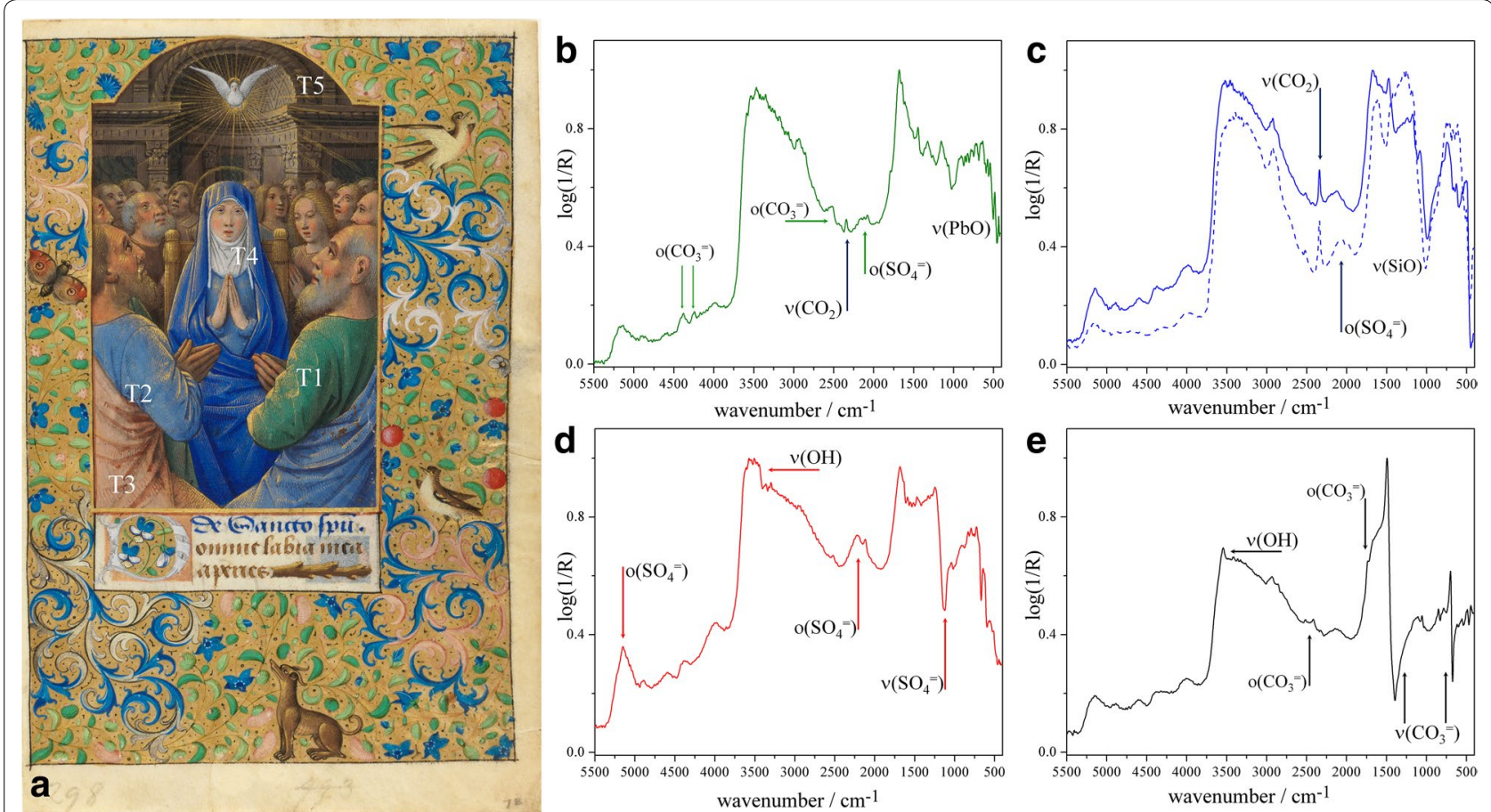

Fig. 4 Cambridge, Fitzwilliam Museum, Marlay Cutting Fr. 5 (a). ER-FTIR spectra collected on the green robe (T1, b), the light blue robe (T2, c), the pink robe $(T 3, \mathbf{d})$ and the white wimple $(T 4, \mathbf{e})$. Characteristic bands for chalk, natural ultramarine, lead-tin yellow, gypsum and lead white are shown; the pigment's overtones and/or combination bands are labeled with o(functional group). The blue dashed line in c represent the spectrum of natural ultramarine/GA paintout

possibly lead-tin yellow. The presence of four inverted absorption bands at 562, 504, 459 and $427 \mathrm{~cm}^{-1}$ could suggest the use of lead-tin yellow type I. The position of these bands is slightly shifted compared to literature data [13] but XRF mapping carried out on this same manuscript fragments identified the presence of both tin and lead in green areas (P. Ricciardi, unpublished technical report), confirming the use of this pigment. Further analysis of the spectrum shows the presence of additional components in this complex mixture, in the form of two white pigments/extenders. The broad absorption at $2516 \mathrm{~cm}^{-1}$, showing a shoulder at $2594 \mathrm{~cm}^{-1}$, together with the well-defined shoulder at $1795 \mathrm{~cm}^{-1}$, can be attributed to the $v\left(\mathrm{CO}_{3}\right)$ combination bands in $\mathrm{CaCO}_{3}$. The presence of calcium carbonate is also supported also by the weak inverted signal at $\approx 1414 \mathrm{~cm}^{-1}$, due to the $v_{3}$ asymmetric stretching. The absorption bands which can be observed in the $2300-2000 \mathrm{~cm}^{-1}$ range can be ascribed to the combination and overtones band of $\mathrm{SO}_{4}^{=}$ in calcium sulphate. Unfortunately, due to the complexity of the spectrum, an unambiguous attribution to a precise calcium sulphate, i.e. gypsum, anhydrite or bassanite, is not possible. The presence of weak but sharp absorptions in the $\mathrm{OH}$ stretching region might suggest gypsum, $\mathrm{CaSO}_{4} \cdot 2 \mathrm{H}_{2} \mathrm{O}$, as the most likely candidate.
The spectrum collected on the blue robe (Fig. 4c) shows the presence of natural ultramarine as the blue pigment. The spectral bands of gypsum and calcite can also be easily recognized, in the region of interest from 2600 to $2000 \mathrm{~cm}^{-1}$. Gypsum is also present in the pink robe (Fig. 4d), as both its overtones and the main vibrational mode are easily detectable. In the region of interest between 2400 and $2000 \mathrm{~cm}^{-1}$ all the combination and overtone bands were identified together with the inverted $v_{3}\left(1149 \mathrm{~cm}^{-1}\right)$ and $v_{3}\left(671\right.$ and $\left.597 \mathrm{~cm}^{-1}\right)$ bands. Moreover the $\mathrm{O}-\mathrm{H}$ stretching shows a derivative-like band with an inflection point at $3410 \mathrm{~cm}^{-1}$. A weak signal due to $\mathrm{CO}_{3}^{=}$group, probably $\mathrm{CaCO}_{3}$, was identified at $2517 \mathrm{~cm}^{-1}$. The Virgin's veil (Fig. 4e) contains lead white. Overtone and combination bands due to carbonate group In hydrocerussite were easily detected at $1738 \mathrm{~cm}^{-1}\left(v_{1}+v_{4}\right)$ and at $2421 \mathrm{~cm}^{-1}$ $\left(2 v_{2}+v_{4}\right)$ together with $v_{3}$, affected by reststrahlen effect) and $v_{4}$, which shows a derivative like feature. Weak signals due to the $\mathrm{SO}_{4}^{=}$overtones in gypsum and $\mathrm{CO}_{3}^{=}$in calcium carbonate were also identified. Lead white also appears to be one of the constituents of the dark background (T5). 


\section{An eleventh-century Gospel Book}

A page from an eleventh-century Gospel Book made in Bavaria (Cambridge, Fitzwilliam Museum, MS McClean 20, fol. 20v, Fig. 5a) was analysed with the main goal to determine the paint binder used by the artist. All the spectra collected on the page are characterised by similar absorptions in the $1800-1500 \mathrm{~cm}^{-1}$ region. Among these, the ones centred at 1678 and $1556 \mathrm{~cm}^{-1}$ can be ascribed to the A I and A II bands in proteinaceous binders, such as EW or WE. The use of a pure proteinaceous binder in the majority of the illumination, can be assumed by the absence of methylene $v+\delta$ combination bands. Only in the pink robe (T1) and in the floral border decoration (T5) the spectral analysis reveals the use of a lipidic binder in combination with a proteinaceous one (Fig. $5 \mathrm{~b}$ ). Both spectra show, in addition to the typical amide bands, also two weak absorptions at $\approx 4334$ and $\approx 4256 \mathrm{~cm}^{-1}$, ascribable to the above mentioned combination bands. Concerning the inorganic components of the pictorial layer, absorptions due to $\mathrm{CO}_{3}^{=}$group were detected in all examined areas. In particular T1, T2, T3 and T5 shows the typical absorption of hydrocerussite, with the main vibration bands $v_{3}, v_{4}$ and $v_{\mathrm{OH}}$ of $\mathrm{Pb}_{3}\left(\mathrm{CO}_{3}\right)_{3}(\mathrm{OH})_{2}$ clearly detectable at $\approx 1415,690$ and $3566 \mathrm{~cm}^{-1}$ (Fig. $5 \mathrm{~b}$ ). Tn $\mathrm{T} 2$ and T3, lead white is presence in association with natural ultramarine, clearly identifiable by its distinctive $v\left(\mathrm{CO}_{2}\right)$ absorption (Fig. 5b). In green areas (T5-7), although XRF shows the presence of $\mathrm{Cu}$ as the main chromophore, no signals ascribable to malachite are detected. These spectra instead show several distinctive absorptions, at 4074, 3452, 3388 and $1982 \mathrm{~cm}^{-1}$, together with three distinct inverted bands, at 584,

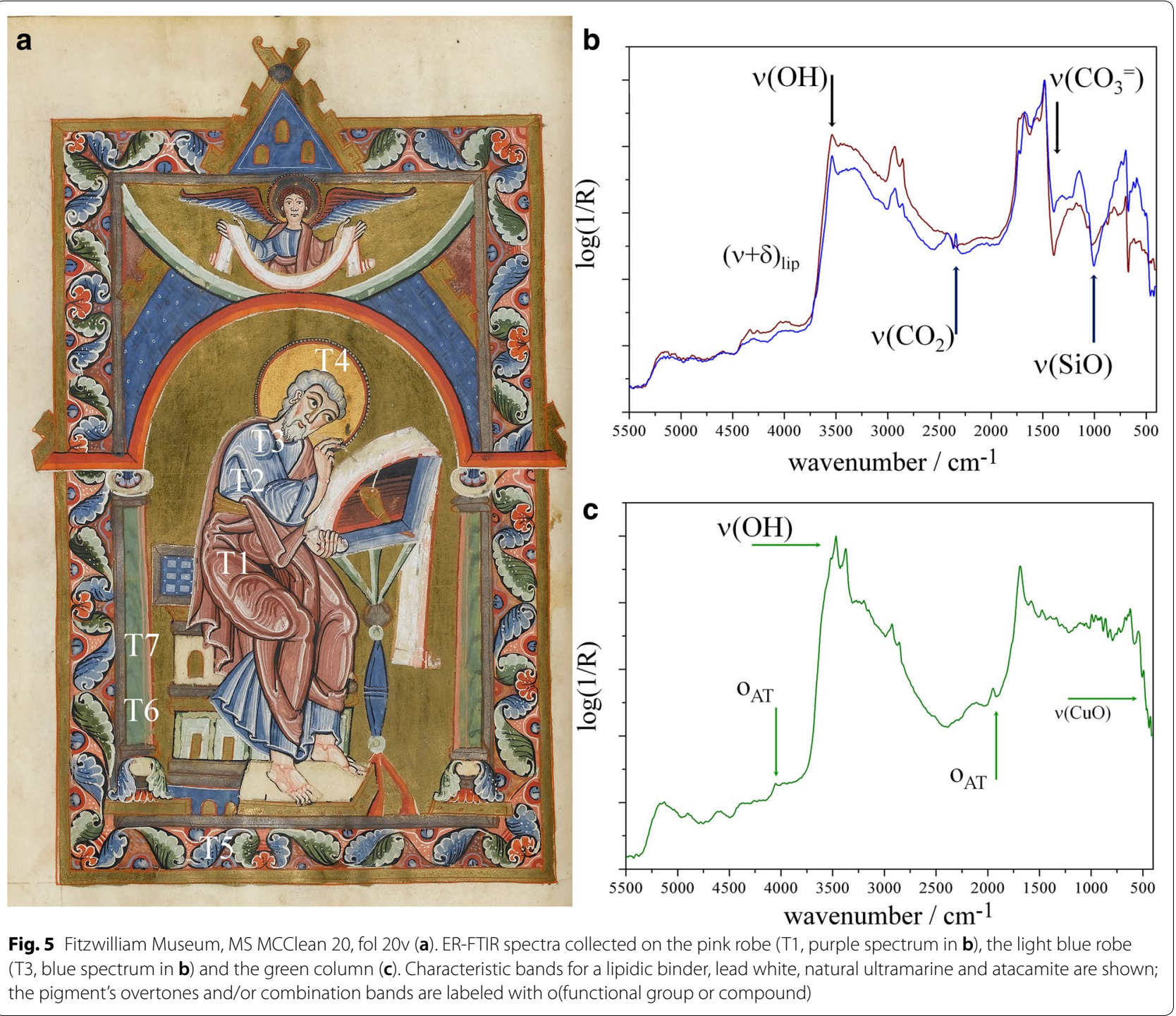


508 and $439 \mathrm{~cm}^{-1}$ (Fig. 5c). These bands can be associated with atacamite, $\mathrm{Cu}_{2} \mathrm{Cl}(\mathrm{OH})_{3}$ [19]. In particular, the lower wavenumber bands are ascribable to the $\mathrm{Cu}-\mathrm{O}$ stretching mode, while the ones at 3452 and $3388 \mathrm{~cm}^{-1}$ correspond to the $\mathrm{OH}$ stretching modes. The two bands at 4074 and $1982 \mathrm{~cm}^{-1}$ could be assigned to overtone and/or combination bands of the $\mathrm{Cu}-\mathrm{Cl}$ and $\mathrm{Cu}-\mathrm{OH}$ normal modes.

\section{A Flemish Book of Hours}

The analysis of two images on an early sixteenth century Flemish Book of Hours (Cambridge, Fitzwilliam Museum, MS 1058-1975, fols. 13v-14r) revealed an interesting difference in the pigments used on the two pages, despite the fact that they face each other in the manuscripts and have long been attributed to the same artist. The measurements performed on fol 13v (Fig. 6a) are dominated by the absorptions of carbonate groups. With the exclusion of the spectrum collected on the blue background (T2), all the spectra show a complex superimposition of distorted bands in the $1800-1300 \mathrm{~cm}^{-1}$ region. The complexity of that region arises from the partial overlap between the $\left(v_{1}+v_{4}\right) \mathrm{CO}_{3}^{=}$overtone, enhanced by the $R_{V}$, and an absorption at $\approx 1684 \mathrm{~cm}^{-1}$. The latter, affected by a derivative-like distortion, can be attributed to the $\mathrm{A} I$ stretching of a proteinaceous binder. In almost all the spectra, A II (at $\left.\approx 1582 \mathrm{~cm}^{-1}\right)$, is partially hidden by the intense and broad inverted band due to the $v_{3}$ of $\mathrm{CO}_{3}^{=}$group. The absence of methylene $v+\delta$ combination bands suggests the use of a purely proteinaceous medium such as EW. Concerning the carbonatecontaining pigments, chalk predominates in grey areas (T1) whereas azurite is present in blue ones (T2). The T1 spectrum is dominated by the intense $v_{3}\left(1411 \mathrm{~cm}^{-1}\right)$ together with $v_{1}+v_{4}\left(1796 \mathrm{~cm}^{-1}\right)$ and $v_{1}+v_{3}$ and/or $2 v_{2}+v_{4}\left(2514 \mathrm{~cm}^{-1}\right)$ absorptions of calcium carbonate. Intense bands of azurite are well detectable in the spectrum T2 (Fig. 6c). The $v(\mathrm{OH})$ with inflection point at $4442 \mathrm{~cm}^{-1}$, with its typical derivative-like feature, is attributable to the hydroxyl groups in $\mathrm{Cu}_{3}\left(\mathrm{CO}_{3}\right)_{2}(\mathrm{OH})_{2}$. A reststrahlen band related to $v_{3}$ in carbonate group is clearly identifiable also in the green jewel (T3, Fig. 6d). Unexpectedly, however, it is not associated to malachite or azurite but, once again, to calcite, with overtones and combination bands of $\mathrm{CaCO}_{3}$ detectable at 1795 $\left(v_{1}+v_{4}\right)$ and $2514\left(v_{1}+v_{3}\right.$ and/or $\left.2 v_{2}+v_{4}\right) \mathrm{cm}^{-1}$ respectively. Excluding the presence of copper carbonates, the nature of the green colour has therefore still to be clarified. Considering the region of interest towards the near infrared, a peculiar broad absorption peak is detectable at $4276 \mathrm{~cm}^{-1}$, exhibiting a shoulder at $4423 \mathrm{~cm}^{-1}$. According to literature data [20], the presence of these two signals, together with a weak absorption at $3533 \mathrm{~cm}^{-1}$ and with an inverted band at $1081 \mathrm{~cm}^{-1}$, can be assigned to brochantite, a green copper sulphate $\left(\mathrm{CuSO}_{4} \cdot 3 \mathrm{Cu}(\mathrm{OH})_{2}\right)$. Calcium carbonate is the predominant signal in the flesh tone area (T4), and it coexists with gypsum in the pink border decoration (T6).

On fol. 14v (Fig. 6b), the binder also seems to be a proteinaceous one, likely the same one used on the previous page, as suggested by the presence of two intense bands, attributable to amide I and amide II (Fig. 6e), in spectra T'1 to T'5. A difference can however be found in the blue and green pigments used. Analysis of the peacock features reveals the presence of smalt and malachite, respectively, rather than the azurite and brochantite identified on fol. 13v. Malachite can be identified on the basis of the evident absorption at $4158 \mathrm{~cm}^{-1}$, due to the combination of the stretching and bending mode of the $\mathrm{OH}$ group, together with the $\mathrm{CO}_{3}^{=}$combination bands $v_{1}+v_{3}$ and/or $2 v_{2}+v_{4}$, at 2536 and $2428 \mathrm{~cm}^{-1}$ and $v_{1}+v_{4}$ at $1802 \mathrm{~cm}^{-1}$. Smalt is clearly present in the blue centre of the feather (T'2 and T'4, Fig. 6e) and identifiably by not only a broad inverted $v_{\mathrm{SiO}}$ absorption at $1072 \mathrm{~cm}^{-1}$, but also an inverted one at $443 \mathrm{~cm}^{-1}$ attributable to metal-O bonds in the glassy matrix of this pigment. All of these spectra actually show evidence for the presence of both pigments, albeit in small quantities (e.g. traces of malachite in T'2, traces of smalt in T'1), due to the relatively large size of the areas analysed using the present set-up.

\section{Conclusions}

This paper confirms ER-FTIR as a powerful tool to study both paint binders and pigments in manuscript illuminations in a completely non-invasive way. The results obtained on the pure binders paintouts show that the discrimination between gum Arabic and egg-based binders is possible and easily achievable. Additionally, due to its lipidic content, egg yolk is distinguishable from egg white. Whole egg, however, can easily be confused with both EY and EW, depending on the amount of lipidic fraction actually present in the specific objects. The identification of inorganic pigments, mixed with different binders, is quite straightforward, thanks to the enhancement of overtones and combination bands by the $R_{\mathrm{V}}$. In the same paintouts, the distinction among different binders is strongly connected with the pigment typology and with the optical properties of the pictorial layer. We observe that oxides, silicates and sulphides do not strongly affect the binders' spectral features. On the contrary, carbonate-containing pigments can seriously interfere with the discrimination of the paint medium. Generally speaking, however, carbonate pigments bound in GA can be discriminated from the same ones mixed with egg-based binders. Still, the $v+\delta$ overtone in lipid can be useful to discriminate EY/WE from EW, although 

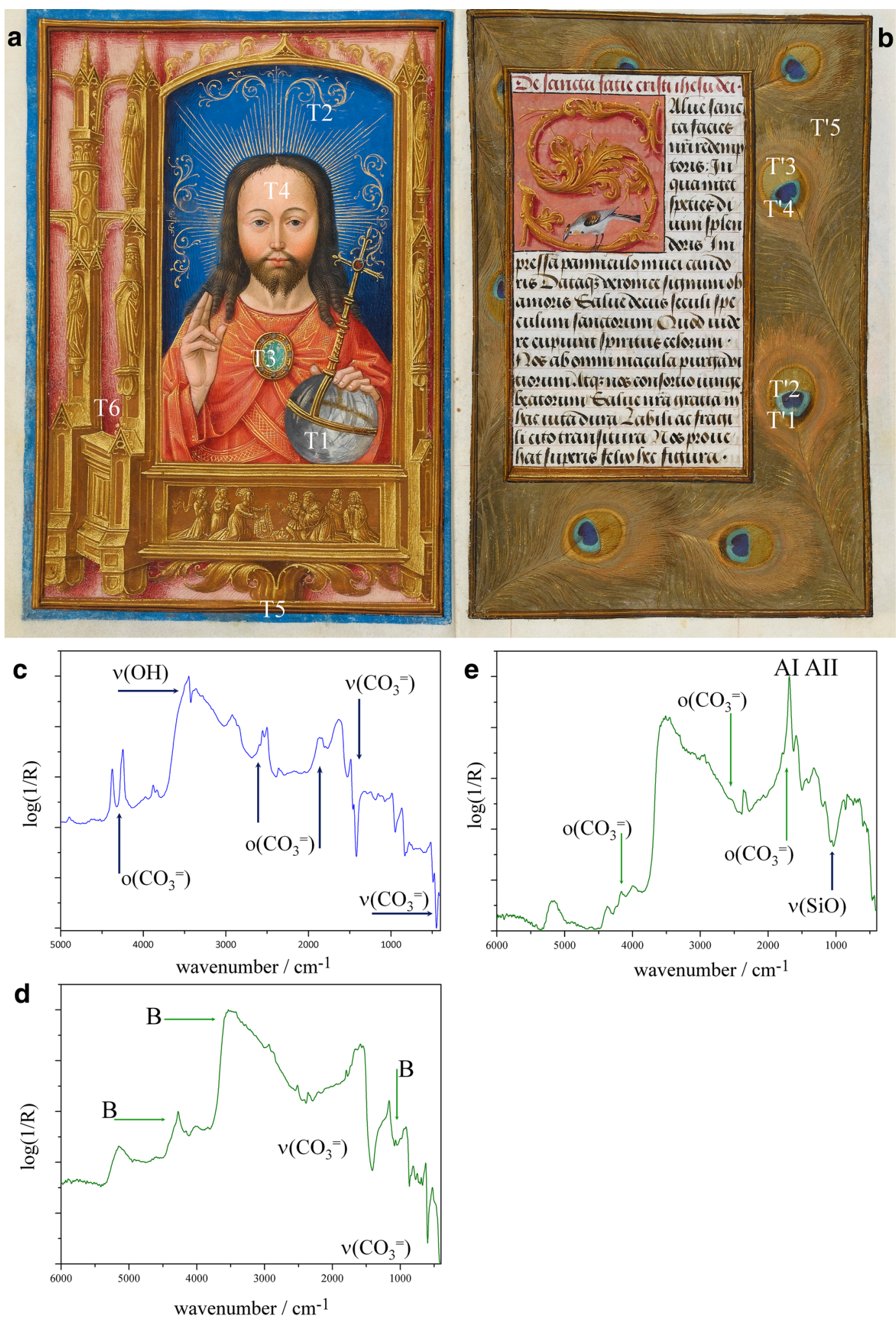

Fig. 6 Cambridge, Fitzwilliam Museum MS 1058-1975, fol. 13v (a) and 14r (b). ER-FTIR spectra collected on the blue background (T2, c), the green jewel $(T 3, \mathbf{d})$ and the blue centre of the peacock feather $\left(T^{\prime} 4, \mathbf{e}\right)$. Characteristic bands for azurite, a proteinaceous binder and smalt are shown. The main absorptions for brochantite are marked with $B$; the pigment's overtones and/or combination bands are labeled with o(functional group) 
the distinction is rather difficult when malachite or azurite are mixed with EW because their combination bands can overlap the above-mentioned lipid marker. Investigations performed on illuminated manuscript fragments and bound volumes allowed the identification of both binders and pigments. Accurate spectral interpretation allowed the identification of different binders in different parts of the same illumination. Moreover the presence of relatively unusual $\mathrm{Cu}$-based pigments such as atacamite and brochantite was revealed.

\author{
Abbreviations \\ ATR: attenuated total reflectance; ER-FTIR: external-reflectance Fourier-trans- \\ form infrared spectroscopy; EW: egg white; EY: egg yolk; FORS: fibre-optics \\ reflectance spectroscopy; FTIR: Fourier-transform infrared spectroscopy; \\ GA: gum Arabic; $\mu$-ATR: micro-ATR; WE: whole egg; XRF: X-ray fluorescence \\ spectroscopy.
}

\section{Authors' contributions}

LN collected, elaborated and interpreted the infrared spectra with assistance from PR. LN and PR wrote the present manuscript. Both authors read and approved the final manuscript.

\section{Author details}

${ }^{1}$ Institute of Condensed Matter Chemistry and Technology for Energy, National Research Council (ICMATE-CNR), C.so Stati Uniti 40, 35127 Padua, Italy. ${ }^{2}$ INSTM Padua Research Unit, C/o ICMATE, C.so Stati Uniti 40, 35127 Padua, Italy. ${ }^{3}$ The Fitzwilliam Museum (University of Cambridge), Trumpington Street, Cambridge CB2 1RB, UK.

\section{Acknowledgements}

The authors wish to thank Dr. Spike Bucklow for preparing the paintouts. Dr. Stella Panayotova is gratefully acknowledged for allowing access to the illuminated manuscripts and providing art-historical background.

\section{Competing interests}

The authors declare that they have no competing interests.

\section{Availability of data and materials}

The datasets analysed during the current study are available from the corresponding author on reasonable request.

\section{Funding}

Partial funding for this research was provided by the University of Cambridge's Returning Carers Scheme.

\section{Publisher's Note}

Springer Nature remains neutral with regard to jurisdictional claims in published maps and institutional affiliations.

Received: 19 September 2018 Accepted: 5 February 2019 Published online: 15 February 2019

\section{References}

1. Casadio F, Toniolo L. The analysis of polychrome works of art: 40 years of infrared spectroscopic investigations. J Cult Herit. 2001;2:71-8.
2. Miliani C, Rosi F, Daveri A, Brunetti BG. Reflection infrared spectroscopy for the non-invasive in situ study of artists' pigments. Appl Phys A Mater Sci Process. 2012;106:295-307.

3. Moura L, Melo MJ, Casanova C, Claro A. A study on Portuguese manuscript illumination: the Charter of Vila Flor (Flower town), 1512. J C Herit. 2007;8:299-306.

4. Bruni S, Cariati F, Casadio F, Toniolo L. Identification of pigments on a XV century illuminated parchment by Raman and FTIR microspectroscopies. Spectrochim Acta Part A. 1999:55:1371-7.

5. Bicchieri M, Monti M, Piantanida G, Pinzari F, Sodo A. Non-destructive spectroscopic characterization of parchment documents. Vib Spectrosc. 2011;55:267-72.

6. Pellegrini D, Duce C, Bonaduce I, Biagi S, Ghezzi L, Colombini MP, Tinè MR, Bramanti E. Fourier transform infrared spectroscopic study of rabbit glue/inorganic pigments mixtures in fresh and aged reference paint reconstructions. Microchem J. 2016;124:31-5.

7. Doherty B, Daveri A, Clementi C, Romani A, Bioletti S, Brunetti B, Sgamellotti A, Miliani C. The Book of Kells: a non-invasive MOLAB investigation by complementary spectroscopic techniques. Spectrochim Acta A. 2013;115:330-6.

8. Vetter W, Schreiner M. Characterization of pigment-binding media systems-comparison of non-invasive in situ reflection ftir with transmission FTIR microscopy. e-PS. 2011;8:10-22.

9. Legrand S, Ricciardi P, Nodari L, Janssens K. Non-invasive analysis of a 15th century illuminated manuscript fragment: point-based vs imaging spectroscopy. Microchem J. 2018;138:162-72.

10. Mannucci E, Pastorelli R, Zerbi R, Bottani CE, Facchini A. Recovery of ancient parchment: characterization by vibrational spectroscopy. J Raman Spectrosc. 2000;31:1089-97.

11. Rosi F, Daveri A, Moretti P, Brunetti BG, Miliani C. Interpretation of mid and near-infrared reflection properties of synthetic polymer paints for the non-invasive assessment of binding media in twentieth-century pictorial artworks. Microchem J. 2016;124:898-908.

12. Vagnini M, Miliani C, Cartechini L, Rocchi P, Brunetti BG, Sgamellotti A. FTNIR spectroscopy for non-invasive identification of natural polymers and resins in easel paintings. Anal Bioanal Chem. 2009;395:2107-18.

13. Kendix EL, Prati S, Mazzeo R, Joseph E, Sciutto G, Fagnano C. Far infrared spectroscopy in the field of cultural heritage. e-PS. 2010;7:8-13.

14. McDevitt NT, Baun WL. Infrared absorption study of metal oxides in the low frequency region $\left(700-240 \mathrm{~cm}^{-1}\right)$. Spectrochim Acta A. 1964;20:799-808.

15. Smith GD, Klinshaw RJ II. The presence of trapped carbon dioxide in lapis lazuli and its potential use in geo-sourcing natural ultramarine pigment. J Cult Herit. 2009;10:451.

16. Dooley KA, Lomax S, Zeibel JG, Miliani C, Ricciardi P, Hoenigswald A, Loew $M$, Delaney JK. Mapping of egg yolk and animal skin glue paint binders in Early Renaissance paintings using near infrared reflectance imaging spectroscopy. Analyst. 2013;138:4838-48.

17. Panayotova S, editor. Colour. The art and science of illuminated manuscripts. London: Harvey Miller Publishers; 2016.

18. Miliani C, Daveri A, Brunetti BG, Sgamellotti $A . \mathrm{CO}_{2}$ entrapment in natural ultramarine blue. Chem Phys Lett. 2008;466:148-51.

19. Frost RL, Martens W, Kloprogge T, Williams PA. Raman spectroscopy of the basic copper chloride minerals atacamite and paratacamite: implications for the study of copper, brass and bronze objects of archaeological significance. J Raman Spectrosc. 2002;22:801-6.

20. Zaffino C, Guglielmi V, Faraone S, Vinaccia A, Bruni S. Exploiting external reflection FTIR spectroscopy for the in situ identification of pigments and binders in illuminated manuscripts. Brochantite and posnjakite as a case study. Spectrochim Acta A. 2015;136:1076-85. 